\title{
Tendencias de la industria de los medios de América del Sur en la transición digital
}

\section{Trends in the Media Industry of South America in the digital transition}

\author{
Francisco Campos-Freire, Jenny Yaguache y Nancy Ulloa ${ }^{1}$ \\ Recibido: 11-05-2017 - Aceptado: 19-07-2017 \\ DOI: https://doi.org/10.26441/RC16.2-2017-A2
}

\begin{abstract}
RESUMEN: Los medios tradicionales (prensa, radio y televisión) de América del Sur presentan en este último tramo de la segunda década del siglo XXI mejores expectativas frente al proceso de transición mediática digital que experimentan las empresas e industrias de la comunicación a nivel global. La confirmación de esta hipótesis se contrasta comparando las tendencias de evolución de la industria de los medios de comunicación latinoamericanos que recogen las bases de datos sectoriales de la Asociación Mundial de Diarios, el informe general de audiencias de televisión de Eurodata, Pew State of the News Media y Global Entertainment \& Media Outlook 2016-2020 con los resultados de una encuesta propia realizada directamente entre gestores de 166 empresas mediáticas de 19 países de este continente. Los gestores de medios de esta área continental afirman que los medios tradicionales crecerán hasta un $5 \%$ y los digitales y publicidad pueden llegar al 10\% o más en los próximos años.
\end{abstract}

Palabras clave: convergencia digital; gestión mediática; innovación; modelos de negocio; muro de pago; publicidad programática.

\begin{abstract}
Traditional media (press, radio and television) in South America have better expectations regarding the process of digital transition faced by communication companies and industries on a global level. This hypothesis is contrasted by comparing two elements. First, the evolution trends of the media sector in Latin America collected by sectorial databases of the World Association of Newspapers and New Publishers, the Eurodata's general audience report, the Pew State of the News Media and the Global Entertainment \& Media Outlook 2016-2020. Second, the results of an own survey to 166 managers from 19 Latin American countries. Media managers from the area confirm that traditional media will grow up to $5 \%$ and digital media and advertising could reach $10 \%$ and more in the coming years.
\end{abstract}

Keywords: digital convergence, media management, innovation, business models, paywall, programmatic advertising.

1 Francisco Campos-Freire es Doctor en Ciencias de la Comunicación por la Universidad de Santiago de Compostela, España y profesor de Gestión de la Empresa Informativa y Audiovisual de la Facultad de Ciencias de Comunicación en la misma universidad. francisco.campos@usc.es, http://orcid.org/0000-0003-1831-1838

Jenny Jovita Yaguache Quichimbo es Doctora en Ciencias de la Comunicación por la Universidad de Santiago de Compostela, España y profesora de la Escuela de Comunicación de la Universidad Técnica Particular de Loja, Ecuador. jjyaguache@utpl.edu.ec, http://orcid.org/0000-0002-5489-4228

Nancy Graciela Ulloa Erazo es Doctora en Ciencias de la Comunicación por la Universidad de Santiago de Compostela, España y profesora de la Escuela de Comunicación de la Pontificia Universidad Católica de Ibarra, Ecuador. nulloa@pucesi.edu.ec, http://orcid.org/0000-0002-8055-1966 


\section{Introducción}

La investigación que recoge este artículo parte de los resultados de observación y análisis pormenorizado de los datos económicos, audiencias, tendencias y gestión de los principales sectores tradicionales de medios de comunicación latinoamericanos, reflejados en las principales fuentes globales de la industria de comunicación, para contrastarlos con una encuesta propia de opinión directa de gestores de sus respectivas organizaciones.

La encuesta fue realizada y tabulada en el último cuatrimestre de 2016, con la participación de gestores de medios de comunicación de 19 países. El objetivo fue comprobar que las tendencias recogidas por los estudios sectoriales macroglobales se correspondían con la opinión de los gestores nacionales de los países sudamericanos. El estudio y la encuesta se denomina Barómetro Internacional de Gestión de la Comunicación, un proyecto que recoge un modelo desarrollado en España y lanzado para América Latina desde la Universidad Técnica Particular de Loja (UTPL) y la Pontificia Universidad Católica de Ibarra (PUCESI), en Ecuador. Se advierte de una debilidad concreta de partida: la ausencia de datos pormenorizados y homogéneos de ingresos, difusión y audiencias país por país, lo que da más valor a la articulación de las fuentes globales citadas y a este proyecto de Barómetro de Gestión de Medios.

Como paso previo al estudio, diseño, realización y presentación de la encuesta de tendencias de la industria de los medios de comunicación en América del Sur revisamos los antecedentes de otras investigaciones globales similares y la caracterización del sistema mediático latinoamericano. Todo ello dominado por las tendencias globales y locales que caracterizan la convergencia y transición digital, la disrupción de los modelos de negocio, la publicidad programática y móvil y los cambios en las audiencias del consumo audiovisual.

\section{Convergencia y transición digital}

Las grandes tendencias globales de la industria de la comunicación, que se recogen de la investigación empírica y de los estudios empresariales del sector, corresponden a procesos multimedia de convergencia y transición digital (Boczkowski, 2004; Dailey, Demo \& Spillman, 2005; García Avilés \& Carvajal, 2008; López \& Pereira, 2010; y Larrondo, Larrañaga, Meso \& Agirreazkuenaga, 2012; entre otros); fuerte innovación disruptiva de los modelos de negocio tradicionales (Christensen, 2015; Mendelson, 2016); operaciones de reconversión mediática (Casero, 2012; Campos, 2015); hiperfragmentación de la producción y megaconcentración de la distribución (Evans, 2015; Miguel de Bustos, 2017); necesidad de nuevas vías para la creación de valor (Picard, 2012); y surgimiento de alternativas emprendedoras, esperanzadoras pero económicamente precarias, de nuevas formas periodísticas alternativas (Deuze, 2017).

Junto a esas grandes tendencias también hay que citar el surgimiento y propagación de las redes sociales digitales a partir del año 2000 que trastocan los 
modelos de los medios tradicionales (Welman, 2001; Boyd \& Ellison, 2007; Campos, 2008); la migración de la publicidad de los viejos a los nuevos medios de acceso gratuito a través de Internet; el rescate del muro de pago digital o paywall, crowfunding, ayudas fiscales y otras de formas financiación (Picard, Beloir-Gagnon \& Ranchordás, 2016); el cambio en las formas del consumo audiovisual lineal masivo, estructurado mediante escaletas de programación y acceso personalizado a través de descargas (Fontaine, 2015); el debate sobre la financiación, reformulación y legitimidad del servicio audiovisual público (EBU, 2012); el uso de algoritmos y la explotación de los contactos producidos por los accesos digitales a través de Big Data (Ranie, Anderson \& Page, 2017; Cukier, 2016); las tecnologías inmersivas, de realidad aumentada y artificial (Pryor, 2000); la eclosión de la publicidad programática y la reacción beligerante contraria a la aparición de bloqueadores (Shiller, 2016; Storey, Reisman, Mayer \& Narayanan, 2017).

\section{Tendencias mediáticas globales}

Una organización de investigación (World Newsmedia, WNMN, 2015) vinculada a la Asociación Mundial de Diarios (WAN-IFRA) realiza también todos los años una encuesta de tendencias sobre la industria de los medios de comunicación. La de 2015, efectuada entre 170 directivos de 50 países, destaca la necesidad de integración entre los distintos departamentos y la capacitación en nuevas competencias relacionadas con los aspectos emergentes de la gestión para los próximos años.

En el mismo sentido, los Big Data y su automatización, mediante algoritmos de inteligencia artificial aplicada a la gestión, el compromiso (engagement) con los usuarios de los medios, las redes sociales y la relación de la comunicación con el Internet de los objetos son las tendencias recogidas por el European Communication Monitor (Zerfass, Verhoeven, Moreno, Tench \& Vercic, 2016), otra encuesta mundial entre 2.710 profesionales de 43 países.

Los medios de comunicación tradicionales se enfrentan a las innovaciones disruptivas (Christensen, 2015) generadas por los nuevos operadores surgidos de la revolución tecnológica de las comunicaciones, de la web 2.0, 3.0 y 4.0, de las redes sociales, del Internet de los objetos y de la inteligencia artificial, respectivamente. Algunas de ellas son el ascenso de la cultura del videostreaming, el uso de algoritmos para personalización la gestión de información, globalización y accesibilidad, inteligencia artificial, uso de realidad virtual y televisión a través de las redes sociales digitales. La innovación disruptiva consiste en romper las reglas tradicionales de los modelos de negocio para arrebatarles una parte de su cuota de mercado.

Dos grandes tendencias industriales (Evans, 2015) emergen hoy en día en la industria mediática global y nacional; por una parte una megaconcentración de corporaciones globales -los Big GAFA (Google, Apple, Facebook y Amazon) presentes en la mayoría de los eslabones del ecosistema de valor de la 
comunicación (Miguel de Bustos, 2017) - y por otra una hiperfragmentación de pequeños o medianos operadores que dependen de aquellas porque son las que controlan el software o las plataformas de distribución de los contenidos.

El modelo tradicional de pago mixto de la industria periodística -basado en la publicidad y el pago del producto o servicio- está en reformulación pero no en cuestión porque los ingresos publicitarios no son suficientes para garantizar la sostenibilidad de muchas actividades. Una buena parte de la tarta publicitaria de la industria mediática global ha sido apropiada en los últimos años por las plataformas y redes digitales de comunicación, en detrimento de los medios tradicionales. La hemorragia de pérdida de publicidad y, por lo tanto, de ingresos que sufren los medios tradicionales es una de las principales preocupaciones que reflejan los gestores consultados por World Newsmedia (WNMN, 2015).

Revela también esta investigación de World Newsmedia que sólo el 5,8\% de los medios consultados reconocía haber generado ganancias superiores al 20 por ciento en el último ejercicio, porcentaje actualmente considerado muy ambicioso pero que, sin embargo, era una realidad presente en esta industria hace una década. En correlación con los indicadores de estancamiento o bajo crecimiento del sector, la opinión dominante $(83 \%$ de los consultados) era favorable a nuevos ajustes y reducciones de costes. Y en ese sentido, cuatro de las principales prioridades sobre reconversión o reestructuración, situaban a los procesos de impresión entre las medidas a tomar, bien concentrando mucho más estos trabajos en imprentas agrupadas o bien suprimiendo las ediciones en papel. Eso es lo que han hecho o están haciendo varios editores de prensa de Norteamérica y Europa.

El sector de la industria mediática en mayor transformación a nivel global es la prensa, que afronta el declive de la impresión y la evolución digital, en medio de una fuerte reconversión, pérdida de difusión e impacto, cierre de cabeceras y empresas, fusiones y despidos de trabajadores. América del Sur y Asia son los continentes en los que la transformación y reconversión va más despacio, porque su evolución es más favorable hasta la fecha, según las estimaciones comparativas a nivel global. No obstante también se registran desapariciones de títulos y ediciones en papel en el ámbito latinoamericano.

La Asociación Mundial de Diarios (WAN-IFRA, 2015) es la fuente global de información más completa sobre la industria de la prensa, con datos por países de la difusión tanto en papel como en digital así como sobre publicidad y evolución del número de títulos o cabeceras periodísticas. Los datos se publican sobre ejercicios anuales cerrados, es decir, un año después de su finalización. En 2016 se publicaron los datos de 2015 y a finales de 2017 se conocerán los del año anterior. Su valor e interés, sin embargo, radica en la observación de sus tendencias horizontales.

Los ingresos de la prensa a nivel mundial en 2015 ascendieron a 168.000 
millones de dólares (157,8 mil millones de euros); 90.000 millones de la divisa norteamericana (53\%) correspondieron a la venta de ejemplares de impresión o de suscripciones digitales frente a 70.000 millones de la misma moneda procedentes de la publicidad. En conjunto, los ingresos de los periódicos se contrajeron un $1,2 \%$ en 2015 y un $5 \%$ en los últimos cinco años.

En torno al 92\% de los ingresos proceden de la prensa impresa, del cobro de ejemplares y publicidad, aunque las ven- tas por el pago de circulación digital (paywall) subieron un 30\% en 2015 y un $85 \%$ en los últimos cinco años. Los ingresos por el pago digital de la prensa ascienden a 3.000 millones de dólares, empezando ya a compensar parcialmente en algunos diarios el deterioro registrado por las bajas de la impresión. Los ingresos de la publicidad digital evolucionaron de 6.182 millones de dólares en 2011 a 9.302 millones en 2015; con 7.276 millones en 2012, 8.107 millones en 2013 y 8.673 millones en 2014 .

Cuadro 1. Evolución mundial de la industria de prensa

\begin{tabular}{|l|c|c|c|c|c|c|}
\hline \multicolumn{1}{|c|}{ Datos } & $\mathbf{2 0 1 1}$ & $\mathbf{2 0 1 2}$ & $\mathbf{2 0 1 3}$ & $\mathbf{2 0 1 4}$ & $\mathbf{2 0 1 5}$ & $\mathbf{2 0 1 1 / 1 5}$ \\
\hline Difusión impresa & 591.302 & 615.257 & 644.737 & 685.158 & 718.783 & $18 \%$ \\
\hline Ingresos totales & 175.641 & 173.960 & 171.604 & 170.007 & 168.018 & $-5 \%$ \\
\hline $\begin{array}{l}\text { Ingresos } \\
\text { en línea }\end{array}$ & 460 & 953 & 1.609 & 2.300 & 3.011 & $85 \%$ \\
\hline $\begin{array}{l}\text { Publicidad de } \\
\text { prensa mundial }\end{array}$ & 87.336 & 85.713 & 80.410 & 75.271 & 70.422 & -24 \\
\hline $\begin{array}{l}\text { Publicidad total } \\
\text { de los medios }\end{array}$ & 414.052 & 432.315 & 446.953 & 466.389 & 494.394 & 16 \\
\hline $\begin{array}{l}\text { Cabeceras de } \\
\text { prensa de pago }\end{array}$ & 12.315 & 11.829 & 10.537 & 9.410 & 10.254 & -20 \\
\hline
\end{tabular}

Fuente: World Press Trends, 2016. Cifras de difusión en millones de ejemplares y de ingresos en millones de dólares.

La difusión de la prensa aumenta de 591 millones de ejemplares diarios distribuidos en 2011 a 718 millones en 2015. El incremento de la difusión a nivel mundial correspondió en los últimos años a los países asiáticos -debido al aumento de la alfabetización- y a cierta estabilidad todavía en algunos países -no en todos- de América del Sur, pero registra importantes retroce- sos en Norteamérica y Europa, también con una disminución del número de cabeceras. Y eso es debido a la baja de los medios tradicionales desaparecidos y a que los nuevos digitales que aparecen ya no se integran en la WAN-IFRA, entidad formada por la fusión de la asociación de editores y la anterior organización de la industria gráfica de la impresión. 
Cuadro 2. Difusión de la prensa mundial e ingresos on line
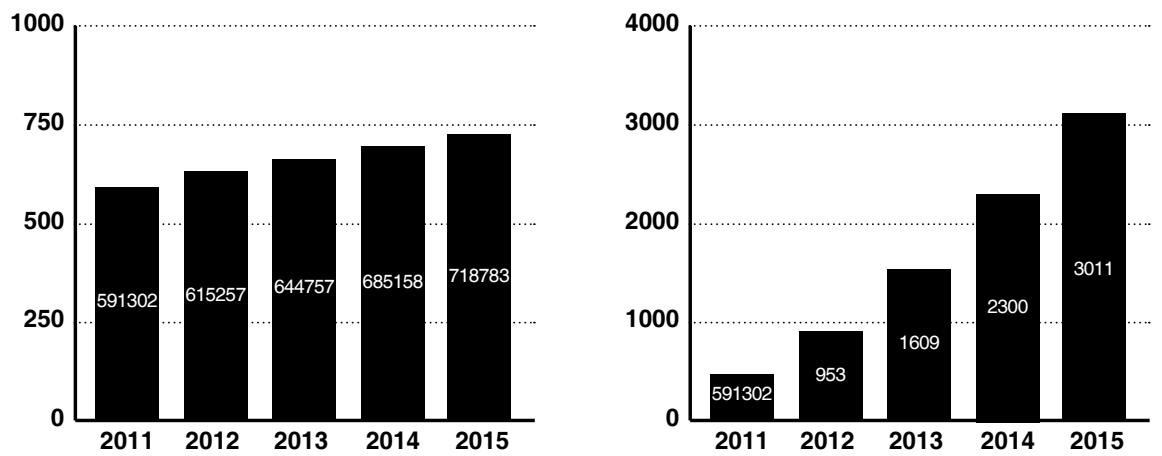

Fuente: World Press Trends WAN-IFRA, 2016. Datos en miles de difusión en papel y de millones de dólares de ingresos de on line.

Según datos de la Asociación Mundial de Diarios 2.700 millones de personas, el $40 \%$ de los adultos del mundo, leen periódicos impresos y 1.400 millones de usuarios de Internet acceden a algún tipo de publicación digital. La lectura de prensa en papel es más colectiva y compartida por varias personas -en familia, en bares, clubes o establecimientos públicos- que la que se realiza a través de dispositivos electrónicos -computadora o teléfono móvil- de acceso individualizado. Ambas constataciones ponen en evidencia que la lectura y el consumo de información en modo alguno ha descendido, pese a que ha bajado la compra y la difusión de los diarios impresos. Esto sitúa el foco de la crisis industrial principalmente en el sistema de distribución, que trasciende del soporte impreso al digital.

La transformación digital y el incremento de lectores en línea se aprecia más en los grandes medios. The Washington Post anunciaba a finales de 2016 un crecimiento del 50\% de lecto- res y del $40 \%$ de publicidad digital en el último año, al batir el récord de $100 \mathrm{mi}$ llones de visitas en Estados Unidos y 30 millones fuera de dicho país. En cambio, la estrategia de muchos diarios regionales y locales del mundo ha sido en los últimos años resistir en papel a base de ediciones más grandes y complementadas con despliegues monográficos.

El negocio de la prensa se sostiene todavía sobre el soporte impreso, a pesar de su pérdida de difusión, porque la comercialización de la publicidad se basa en las cifras de circulación del papel debido a que tiene un modelo tradicional de medición consolidado que no ha sido capaz de ser reemplazado aún por las nuevas métricas digitales, carentes de credibilidad y consenso por parte de las marcas anunciantes. Pero eso está cambiando y pronto variarán las tornas porque la publicidad programática (procesada mediante algoritmos) se está empezando a imponer. Por ello otro reto importante para la prensa en los 
próximos años es la consolidación de un sistema de medición combinada de papel, digital y acceso a través de plataformas.

\section{Modelos de negocio}

La convergencia digital abrió las puertas a la innovación y ésta trastocó los modelos de negocio tradicionales o generó otros nuevos. Un modelo de negocio es una representación simbólica y simplificada de una realidad compleja, que se usa para dar forma a una síntesis de relaciones productivas, comerciales y de interacción de una empresa con sus clientes y grupos de interés (Drucker, 1954; Timmers, 1998; Amit \& Zott, 2001; Magretta, 2002; Osterwalder, Pigneur \& Tucci 2005; Mendelson, 2015).

La definición de un modelo de negocio se basa en la determinación de nueve elementos: segmentación de clientes objetivos, propuesta de valor del producto o servicio para ellos, canales de comercialización y distribución, sistema de relaciones con los usuarios de los servicios, fuentes de ingresos y precios, recursos o activos claves de valor, actividades esenciales para que el modelo funcione, asociaciones con las redes de valor de proveedores y socios y estructuras de costes. En la industria mediática actual conviven distintos modelos de negocio (mixto de pago de producto o servicio y publicidad, solo de publicidad, de abono exclusivo o suscripción, canon, financiación pública mediante subvención, freemium, de afiliación, colaboración, filantropía o mecenazgo, membresía o $\mathrm{P} 2 \mathrm{P}$ ) según la estrategia de cada una de las empresas o corporaciones.
Los modelos de la industria mediática tradicional se desarrollaron a través del pago del producto (libros, prensa y televisión de abono), publicidad (prensa, radio y televisión), canon y subvención (televisión pública) y suscripción (diarios, revistas y televisión encriptada). Internet cambió la lógica de funcionamiento de los negocios de la economía industrial tradicional, basada en la estructura lineal de su cadena de valor. En la economía digital la cadena de valor se ha desestructurado y fragmentado a favor de nuevas formas organizativas o redes de valor como consecuencia de la innovación. Esas nuevas formas cambiaron los procesos de producción, distribución y de relación (interacción) con los clientes.

Philip Evans (2015) señala que la reaceleración del cambio tecnológico sobre la gestión de la información (big data) y las redes transforman las organizaciones. Destaca dos tendencias contrapuestas: la deconstrucción de las cadenas de valor de las industrias tradicionales y la polarización de las economías de masa en torno a la fragmentación, por una parte, y a la megaconcentración, por otra. Así, según Kotter (2015), las nuevas organizaciones para un mundo en cambio acelerado deben tener una estructura dual para la transición y una constelación en red abierta de cara al futuro, con estrategias y formas de trabajo policéntricas, flexibles, autónomas, virtuales y basadas en resultados (Thomson, 2015).

Las redes de valor (Allee, 2009) son grupos, comunidades o plataformas especializadas (de negocios, de servicios, 
etc.) de organizaciones, empresas y personas que colaboran y compiten al mismo tiempo. Por esas cañerías virtuales discurre el flujo de valor de la comunicación y la relación social que se articula a través de Internet dando lugar a nuevos modelos de negocio. Se convierten de esa forma en redes digitales de valor con múltiples nodos o puntos de entrada y salida que enlazan con una compleja diversidad de actores involucrados (Feng \& Jason, 2002). Las siglas de Google, Apple, Facebook y Amazon se han convertido en el acrónimo de los GAFA, grandes redes de negocios (Alphabet, la matriz de las empresas de Google se constituyó como tal en 2015) que dominan la economía digital de la información, la comunicación y los datos (Miguel de Bustos \& Casado, 2016).

La concentración y el control del negocio mediático -acceso a la información, contenidos, publicidad y datos- por parte de esos nuevos megaoperadores infomediarios es una de las prioridades de la industria editorial tradicional, que se manifiesta en las encuestas de la WAN-IFRA y en las campañas que en algunos países se agitan contra el duopolio de Google y Facebook. The Press Gazette del Reino Unido recogía en abril de 2017 un informe que estimaba que en 2020 el 71 por ciento de la publicidad de ese mercado sería monopolizado por esos dos grandes gigantes de la info comunicación.

\section{Publicidad digital y programática}

A nivel mundial los ingresos por publicidad ya son más altos en Internet que en la televisión tradicional. El creci- miento estimado para 2020 de la publicidad en Internet alcanza el $11,1 \%$ y un total de 260.400 millones de dólares, aunque con problemas por la aparición de los bloqueadores de anuncios, que se estima que ya están instalados en un 25 por ciento de las computadoras de todo el mundo.

La introducción de los bloqueadores encendió todas las alarmas de la Interactive Advertising Bureau (IAB), la asociación de la publicidad digital, que considera a dichos programas informáticos como una "catástrofe que puede acabar con la fuente de financiación de la llamada gratuidad de Internet". Por el contrario, los defensores de los ad blockers destacan las ventajas de su control de la privacidad, velocidad de acceso, más ancho de banda, eliminación de contenidos indeseados y mejor experiencia de la navegación.

La publicidad móvil y la programática son dos tendencias que crecen rápidamente, provocando impacto también en la industria mediática tradicional, porque escapan de su control hacia nuevos operadores de telecomunicaciones e Internet. La publicidad móvil crecerá un 19,6\%, hasta 84.800 millones de dólares (PWC, 2016), tendencia al alza que también registrarán los anuncios de pago preferente de los buscadores y la contratación en tiempo real (RTB) de la publicidad programática. A pesar de los bloqueadores, de la medición dudosa y del riesgo de seguridad o fraude para las marcas, el desarrollo de la publicidad digital es incuestionable, protagonizada además por nuevos y grandes operadores convergentes. 
Según el Top 30 Global Media Owners (Zenith 2017), Google y Facebook acapararon el 20 por ciento de toda la publicidad global de los medios de comunicación. Alphabet, el holding empresarial de Google, sumó 79.400 millones de ingresos publicitarios en 2016, tres veces más que la mencionada red social, que alcanzó 26.900 millones; y en tercer lugar se situó la compañía norteamericana de audiovisual y telecomunicaciones Comcast con 12.900 millones de dólares. Las 30 principales compañías de medios (entre ellas, Disney, Verizon, Twitter, Yahoo, Microsoft o Baidu) generaron en conjunto 132.800 millones de dólares de ingresos publicitarios en línea en 2016, un 73 por ciento de la tarta publicitaria digital y un $24 \%$ del total de publicidad.

Cuadro 3. Publicidad programática y operadores digitales
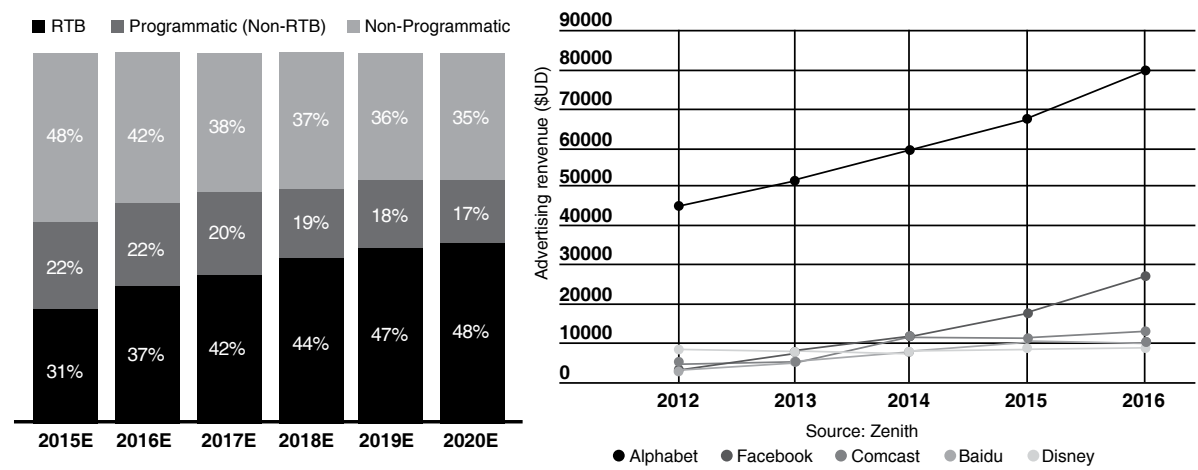

Fuente: Worlds Press Trends y Zenith Optimedia

La publicidad programática es aquella que ofrece la posibilidad de contratar inserciones en tiempo real (Real Time Bidding), manejando y combinando múltiples variables de los públicos (edad, profesión, género, posición social, ubicación geográfica, franja horaria determinada, aficiones e intereses, comportamiento en la red, etc.), mediante software de datos sobre los usuarios de la red y de los respectivos algoritmos de gestión predictiva. El control de los datos, su medición, disponibili- dad y algoritmo de gestión de la contratación se convierte en el valor central del sistema.

\section{Cambios en TV y audiencias}

La publicidad y su predicción para la planificación programática -la que utiliza Netflix para sus campañas de marketing, p.e.- son también herramientas estratégicas de la nueva industria audiovisual. En términos de liderazgo, tras el impulso digital de la industria publicitaria, sigue la televisión, la 
prensa, la edición de libros de ficción y educación, el cine y la música.

El sector audiovisual afronta las sucesivas transiciones del analógico al digital y de la televisión lineal (reducción de su consumo en doce países europeos) a la no lineal, dominada por el acceso bajo demanda (streaming), con una creciente tendencia por parte de los públicos más jóvenes y usuarios en movilidad al incre- mento de las descargas bajo petición, generando una gran fragmentación de audiencias, crisis de su sistema tradicional de medición y valorización, pérdida de poder competitivo de la radiotelevisión pública, concentración de grupos audiovisuales privados tradicionales y fuerte entrada de nuevos operadores de telecomunicaciones e infomediarios digitales (Netflix, Amazon, Youtube, etc).

Cuadro 4. Mercado global de la industria televisiva

\begin{tabular}{|l|r|r|r|r|r|r|}
\hline Ingresos mII\$ & \multicolumn{1}{c|}{$\mathbf{2 0 1 1}$} & \multicolumn{1}{c|}{$\mathbf{2 0 1 2}$} & \multicolumn{1}{c|}{$\mathbf{2 0 1 3}$} & \multicolumn{1}{c|}{$\mathbf{2 0 1 4}$} & \multicolumn{1}{c|}{$\mathbf{2 0 1 5}$} & \multicolumn{1}{c|}{ 2011/15 } \\
\hline Publicidad TV & 120.462 & 125.908 & 129.151 & 135.763 & 137.320 & $14 \%$ \\
\hline TV pública & 24.248 & 24.377 & 24.896 & 25.285 & 25.414 & $5 \%$ \\
\hline TV de pago & 147.042 & 155.093 & 162.355 & 170.655 & 178.167 & $21 \%$ \\
\hline Total TV & 291.752 & 305.378 & 316.402 & 331.703 & 340.901 & $17 \%$ \\
\hline
\end{tabular}

Fuente: OFCOM 2016 y PWC Global Entertaiment Media Outlook 2016-2020. Datos en millones de dólares.

No desciende el consumo de televisión sino que se diversifica a través de distintas plataformas, pantallas y usos. También se mantiene el crecimiento del mercado audiovisual y de la televisión multicanal pero con mayor concentración de operadores. Los datos del regulador británico de comunicaciones (OFCOM, 2016) y del análisis mundial de PWC, que se recogen en el cuadro 4, constatan esas tendencias a través de un incremento del 17 por ciento en los ingresos globales de la industria televisiva entre 2011 y 2015 , que asciende al 21 $\%$ en la televisión de pago.

\section{Sistema mediático latinoamericano}

El sistema de medios es tan múlti- ple y complejo como la realidad sociopolítica y económica del continente latinoamericano, donde se entrecruzan estructuras y economías duales (Díaz Nosty, 2007). La clásica caracterización de los sistemas comparados de Hallin y Mancini (2007), que aún no contemplaba la realidad de la convergencia digital, sigue siendo operativa para clasificar los medios latinoamericanos dentro de un sistema híbrido, en el que se combinan características del modelo pluralista polarizado, típico de los países del sur de Europa, y del liberal característico del área anglosajona.

La prensa, como producto de élite, tiene fuertes raíces de polarización 
político partidista conservadora, aunque en su formato y estrategia comercial ha copiado más del modelo norteamericano que del europeo. Sin embargo, la televisión nace y se desarrolla inspirada en el modelo comercial norteamericano financiado a través de la publicidad o mediante suscripción de pago. No sólo tienen fuerte implantación los sistemas de distribución por cable y las franquicias norteamericanas sino también los doblajes, subtitulados o producciones ajenas de Hollywood y Miami. Rocagliolo (2003) destaca tres atipicidades del sistema audiovisual latinoamericano: inspiración comercial en el modelo norteamericano, desarrollo marginal de la televisión pública y emergencia de formas alternativas de comunicación social comunitaria desarrollada por asociaciones, fundaciones, Universidades y comunidades locales.

El acceso al poder de nuevos gobiernos populistas y del llamado socialismo del siglo XXI en Venezuela, Ecuador, Argentina o Bolivia abrió un panorama de nuevas políticas de responsabilidad social de la comunicación que apostaron por la democratización del reparto del espectro digital de licencias de emisión, freno y contrapeso a los crecientes procesos de concentración convergente de grupos de prensa y televisión (Mastrini y Becerra, 2006) y potenciación de la televisión pública. Sin embargo, más allá del espíritu bien o mal intencionado de las nuevas leyes de comunicación, los objetivos y resultados de esas políticas se han materializado en confrontaciones fácticas por la hegemonía mediática entre los poderes gubernamentales y mediáticos.

La irrupción en el panorama comunicacional de los nuevos medios digitales globales o locales y de las plataformas de redes sociales amplía exponencialmente en el nuevo siglo el ecosistema mediático, dejando obsoletas algunas de esas leyes y políticas nacionales -pensadas para los medios tradicionales- por la desterritorialización de sus lugares de emisión y su difusión global masiva a través de Internet así como de interacciones reticulares de millones de personas que se convierten en receptores, productores, emisores y redifusores de autocomunicación (Castells, 2009). 
Cuadro 5. Prensa e inversión publicitaria de países latinoamericanos

\begin{tabular}{|c|c|c|c|c|c|}
\hline Países & 2010 & 2011 & 2012 & 2013 & 2014 \\
\hline \multicolumn{6}{|c|}{ TíTULOS DE PRENSA DE PAGO } \\
\hline Argentina & 41 & 40 & 40 & 37 & 36 \\
\hline Brasil & 642 & 550 & 550 & 500 & 500 \\
\hline Chile & 50 & 60 & 60 & 50 & 50 \\
\hline Colombia & 45 & 56 & 57 & 56 & 53 \\
\hline Ecuador & 41 & 41 & 40 & 40 & 40 \\
\hline Perú & 100 & 100 & 95 & 95 & 95 \\
\hline Venezuela & 109 & 109 & 100 & 100 & 100 \\
\hline \multicolumn{6}{|c|}{ DIFUSIÓN DE LA PRENSA DE PAGO (miles de ejemplares) } \\
\hline Argentina & 1.080 & 1.157 & 1.043 & 993 & 926 \\
\hline Brasil & 8.358 & 8.651 & 8.806 & 8.480 & 8.478 \\
\hline Chile & 554 & 528 & 510 & 490 & 490 \\
\hline Colombia & 1.200 & 1.200 & 1.200 & 1.000 & 990 \\
\hline Ecuador & 660 & 660 & 500 & 500 & 500 \\
\hline Perú & 1.659 & 1.680 & 1.500 & 1.500 & 1.500 \\
\hline Venezuela & 1.810 & 1.815 & 1.750 & 1.750 & 1.750 \\
\hline \multicolumn{6}{|c|}{ PUBLICIDAD EN PRENSA DE PAGO (millones de dólares) } \\
\hline Argentina & 487 & 671 & 815 & 994 & 1.217 \\
\hline Brasil & 1.220 & 1.266 & 1.275 & 1.228 & 1.084 \\
\hline Chile & 254 & 290 & 281 & 281 & 258 \\
\hline Colombia & 447 & 537 & 484 & 460 & 403 \\
\hline Ecuador & 97 & 95 & 100 & 93 & 90 \\
\hline Perú & 91 & 98 & 103 & 106 & 107 \\
\hline Venezuela & 249 & 263 & 305 & 267 & 303 \\
\hline \multicolumn{6}{|c|}{ INVERSIÓN TOTAL DE PUBLICIDAD EN MEDIOS (millones de dólares) } \\
\hline Argentina & 1.458 & 1.918 & 2.412 & 3.169 & 4.426 \\
\hline Brasil & 9.741 & 10.586 & 11.245 & 12.044 & 15.314 \\
\hline Chile & 941 & 1.089 & 1.114 & 1.163 & 1.142 \\
\hline Colombia & 1.768 & 2.157 & 2.388 & 2.516 & 1.872 \\
\hline Ecuador & 368 & 454 & 410 & 422 & 448 \\
\hline Perú & 514 & 595 & 660 & 715 & 758 \\
\hline Venezuela & 930 & 982 & 1.156 & 1.173 & 1.466 \\
\hline
\end{tabular}

Fuente: World Press Trends Database (WAN-IFRA, 2016). 
La eclosión de esas nuevas formas de autocomunicación, a través de la expansión de Internet y de la telefonía móvil en los países latinoamericanos, diluyen más la hegemonía y el negocio de los grupos mediáticos tradicionales que las políticas de control de los gobiernos opositores de turno. El impacto es más notorio en la prensa impresa de pago que en la televisión y otras formas de comunicación. Las cifras de World Press Trends Database, que recoge el cuadro 5 , muestran cómo desaparecen cabeceras de prensa de pago y descienden tanto los ingresos por difusión como por publicidad. Se reproducen sólo los datos de siete países latinoamericanos porque son los únicos de esta región que analiza el informe mundial de la Asociación Mundial de Diarios (WAN-IFRA, 2016).

Frente a los descensos paulatinos en el número de periódicos impresos y en la circulación de los que se mantienen, algunos países (Argentina, Chile, Perú y Venezuela) logran sostener la inversión publicitaria de la prensa, cuando las caídas son más notables por el contrario en Brasil, Colombia y Ecuador. Esta es la misma tendencia que se registra en Europa, Norteamérica y Australia, aunque en la mayoría de esos países ya avanza la introducción del sistema de pago digital a través del muro de pago (paywall), algo más lenta y menos frecuente todavía en el continente sudamericano. La media de ingresos sobre el total en algunos de esos países avanzados del paywall alcanza el 20 por ciento.
Otro dato destacado por WAN-IFRA es el tiempo de lectura de la prensa impresa. En Colombia los periódicos impresos tienen un $70 \%$ de audiencia mensual y el lector promedio de este país le dedica una hora de atención al diario. En Chile el porcentaje de cobertura es del $73,6 \%$ y la media de lectura al día se contabiliza en 28 minutos y en Brasil los impresos llegan al 41,5\% (en 9 áreas metropolitanas) de la población, con 27 minutos de media del lectorado. En contraste, la WAN llama la atención sobre el tiempo de acceso a nivel global a la información, a través de aplicaciones y navegadores, que es de dos horas y cuatro minutos, según datos de Knight Foundation y Nielsen Study.

Los cambios en el panorama de la televisión también son significativos. A pesar de que el consumo de televisión crece en América del Sur, la fragmentación de audiencias de sus canales es notable, a la vista de las cifras de Eurodata TV, que recoge resultados de la mayor parte de los países del mundo del respectivo año anterior. Los datos de 2016 no serán accesibles tampoco hasta finales de 2017. Salvo en los grandes mercados audiovisuales de Brasil, Colombia, Perú, Panamá y Paraguay las audiencias de los canales líderes no superan el $20 \%$ de share. Se registran también en la mayor parte de los canales latinoamericanos pérdidas de audiencias en 2015 con respecto al año anterior. 
Cuadro 6. Audiencias de los canales de televisión en 2015, según Eurodata 2016

\begin{tabular}{|c|c|c|c|c|c|c|c|c|c|}
\hline Canal & Propiedad & $\begin{array}{l}\text { Audiencia } \\
\text { en total } \\
\text { de } 2015\end{array}$ & \begin{tabular}{|l} 
Evolución \\
sobre \\
2014 \\
\end{tabular} & $\begin{array}{l}\text { Prime } \\
\text { time } \\
2015\end{array}$ & Canal & Propiedad & $\begin{array}{l}\text { Audiencia } \\
\text { en total de } \\
2015\end{array}$ & $\begin{array}{l}\text { Evolución } \\
\text { sobre } \\
2014 \\
\end{array}$ & $\begin{array}{l}\text { Prime } \\
\text { time } \\
2015 \\
\end{array}$ \\
\hline ARGENTINA & \multicolumn{2}{|c|}{ Universo: 14.328 .100} & \multicolumn{2}{|c|}{ Panel: 3.676} & ECUADOR & \multicolumn{2}{|c|}{ Universo: 4.700 .500} & \multicolumn{2}{|c|}{ Panel: 1.930} \\
\hline Telefé & Privada & 10,9 & $-1,1$ & 13,1 & Ecuavisa & Privada & 14.6 & -0.6 & 15.9 \\
\hline El 13 & Privada & 10,1 & 0,2 & 13,1 & TC Televisión & Privada & 13.1 & $-2-2$ & 14.3 \\
\hline América 2 & Privada & 6,1 & $-0,1$ & 5,7 & Red Telesistema & Privada & 11.4 & 0.2 & 10.9 \\
\hline Canal 9 & Pública & 5,6 & $-0,6$ & 5,2 & Gama TV & Privada & 8.8 & 0.5 & 9.9 \\
\hline TV Pública & Pública & 4,1 & $-0,6$ & 5,4 & Canal Uno & Privada & 8.4 & 1.8 & 10.4 \\
\hline BRASIL & \multicolumn{2}{|c|}{ Universo: 67.721 .000} & \multicolumn{2}{|c|}{ Panel: 16.003} & GUATEMALA & \multicolumn{2}{|c|}{ Universo: 3.246 .200} & \multicolumn{2}{|c|}{ Panel: 1.414} \\
\hline Globo & Privada & 34.3 & -0.2 & 38.0 & Televisiete & Privada & 11.4 & -1.3 & 13.4 \\
\hline SBT & Privada & 13.9 & 1.1 & 12.6 & $\begin{array}{l}\text { Canal 3 El } \\
\text { Supercanal }\end{array}$ & Privada & 9.2 & -0.4 & 10.6 \\
\hline Record & Privada & 12.9 & 1.3 & 13.6 & Trecevisión & Privada & 3.7 & -1.6 & 3.7 \\
\hline TV Bandeirantes & Privada & 4.0 & -0.7 & 4.0 & Teleonce & Privada & 3.6 & -1.7 & 4.0 \\
\hline Rede TV! & Privada & 1.3 & -0.3 & 1.3 & Azteca 31 & Privada & 1.6 & -0.7 & 1.7 \\
\hline CHILE & \multicolumn{2}{|c|}{ Universo: 6.600 .200} & \multicolumn{2}{|c|}{ Panel: 2.025} & PANAMÁ & \multicolumn{2}{|c|}{ Universo: 1.832 .000} & \multicolumn{2}{|c|}{ Panel: 1.054} \\
\hline Megavision $\mathrm{CH} 9$ & Privada & 19.3 & 2.9 & 22.0 & Telemetro & Privada & 23.5 & 0.8 & 24.1 \\
\hline $\begin{array}{l}\text { Univ Católica } \\
\mathrm{CH} 13\end{array}$ & Privada & 13.2 & -0.2 & 13.7 & TVN & Privada & 18.2 & -2.5 & 21.3 \\
\hline Chilevisión $\mathrm{CH} 11$ & Privada & 13.1 & -0.1 & 14.7 & $\mathrm{RPC}$ & Privada & 6.0 & -1.8 & 5.7 \\
\hline $\begin{array}{l}\text { Televisión Nac } \\
\mathrm{CH} 7\end{array}$ & Pública & 9.8 & -3.1 & 8.2 & TV Max & Privada & 5.0 & -1.7 & 5.8 \\
\hline La Red CH4 & Privada & 2.4 & -0.9 & 1.9 & PARAGUAY & \multicolumn{2}{|c|}{ Universo: 1.954 .900} & \multicolumn{2}{|l|}{ Panel: 875} \\
\hline COLOMBIA & \multicolumn{2}{|c|}{ Universo: 18.999 .700} & \multicolumn{2}{|c|}{ Panel: 3.244} & S.N.T. Canal 9 & Privada & 23.2 & -4.7 & 22.2 \\
\hline Canal Caracol & Privada & 23.8 & -1.6 & 25.7 & Telefuturo & Privada & 22.9 & -3.2 & 23.1 \\
\hline Canal RCN & Privada & 19.6 & 1.3 & 22.9 & La Tele & Privada & 10.1 & -3.1 & 9.2 \\
\hline CityTv & Privada & 1.9 & -0.3 & 1.6 & El Trece & Privada & 8.0 & -3.7 & 10.0 \\
\hline Canal Uno & Mixto & 1.2 & 0.0 & 1.8 & Paravisión & Privada & 6.0 & -2.2 & 6.1 \\
\hline Señal Colombia & Pública & 1.0 & 0.0 & 0.7 & PERÚ & \multicolumn{2}{|c|}{ Universo: 9.322 .700} & \multicolumn{2}{|c|}{ Panel: 1.862} \\
\hline COSTA RICA & \multicolumn{2}{|c|}{ Universo: 2.380 .700} & \multicolumn{2}{|c|}{ Panel: 1.146} & América TV & Privada & 21.4 & -0.5 & 24.5 \\
\hline Repretel Canal 6 & Privada & 16.7 & 0.4 & 14.7 & $\begin{array}{l}\text { Frecuencia } \\
\text { Latina } \\
\end{array}$ & Privada & 16.9 & 0.8 & 17.3 \\
\hline Teletica Canal 7 & Privada & 15.8 & -1.8 & 17.3 & ATV & Privada & 10.0 & -2.4 & 12.1 \\
\hline Repretel C11 & Privada & 8.8 & -0.5 & 11.6 & Paramericana & Privada & 3.8 & 0.3 & 4.9 \\
\hline Canal 9 & Privada & 2.4 & -0.6 & 2.8 & Global TV & Privada & 2.3 & -1.0 & 2.2 \\
\hline Repretel Canal 4 & Privada & 1.8 & -0.7 & 1.9 & URUGUAY & \multicolumn{2}{|c|}{ Universo: 1.182 .800} & \multicolumn{2}{|c|}{ Panel: 743} \\
\hline DOMINICANA & \multicolumn{2}{|c|}{ Universo: 3.718 .047} & \multicolumn{2}{|c|}{ Panel: 1.429} & Teledoce & Privada & 18.8 & -3.2 & 20.2 \\
\hline Telesistema 11 & Privada & 16.5 & -1.0 & 18.5 & Canal 10 Saeta & Privada & 18.3 & 1.3 & 22.8 \\
\hline Telemicro 5 & Privada & 13.1 & 1.4 & 14.8 & Montecarlo & Privada & 12.3 & -0.7 & 12.3 \\
\hline Antena Latina & Privada & 9.4 & -0.8 & 7.6 & $\begin{array}{l}\text { TV Nacional } \\
\text { Uruguay }\end{array}$ & Pública & 3.7 & 0.7 & 2.9 \\
\hline Color Visión 9 & Privada & 6.7 & 2.7 & 7.4 & VENEZUELA & Universo: 9. & 404.021 & Panel: 4.63 & \\
\hline Teleantillas 2 & Privada & 6.6 & -1.8 & 6.1 & Venevisión & Privada & 16.6 & -2.8 & 16.4 \\
\hline & & & & & Televen & Privada & 13.1 & -0.7 & 14.2 \\
\hline $\begin{array}{l}\text { Fuente: Informe E } \\
\text { Television Year in }\end{array}$ & $\begin{array}{l}\text { Eurodata TV V } \\
\text { the World } 20\end{array}$ & Vorldwide-On & & & $\begin{array}{l}\text { Venezolana de } \\
\text { Televisión }\end{array}$ & Pública & 5.4 & 0.5 & 5.2 \\
\hline & & & & & Globovisión & Privada & 2.3 & -0.3 & 2.1 \\
\hline & & & & & Meridiano & Privada & 2.0 & -0.3 & 3.0 \\
\hline
\end{tabular}

Fuente: Eurodata, 2016. En la edición de Eurodata TV correspondiente a 2015 no se incluyen datos de México, lo que imposibilita su reproducción. 
El consumo medio mundial de televisión, sobre un universo global de 3.800 millones de telespectadores, fue en 2015 de tres horas con 3 minutos, diez minutos menos que en 2014. Por continentes, el tiempo de consumo de televisión fue el siguiente: Norteamérica, 4 horas y $29 \mathrm{mi}-$ nutos; Europa, tres horas y 55 minutos; Asia, dos horas y 32 minutos; Oceanía, tres horas y 9 minutos; África, tres horas y 12 minutos; y América del Sur, tres horas y 38 minutos. Las dos únicas regiones donde creció el consumo de televisión en 2015 fueron África y América del Sur, con un aumento de 5 minutos respecto a 2014 en esta región. Y el país de mayor consumo televisivo del mundo es Arabia Saudí con 6 horas y 44 minutos.

Cuadro 7. Consumo de televisión en América del Sur

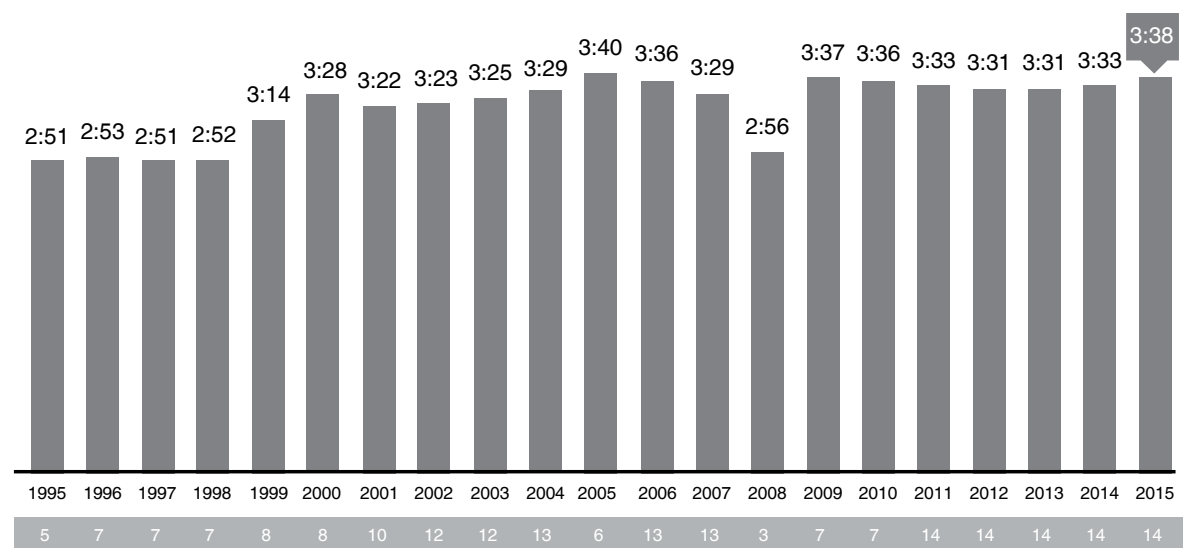

Lista de países incluidos en el anuario de audiencias de 2015 de Eurodata TV (One TV Year in the World, 2016): Argentina, Brasil, Chile, Colombia, Costa Rica, República Dominicana, Ecuador, Guatemala, Panamá, Paraguay, Perú, Puerto Rico, Uruguay y Venezuela.

Otra tendencia en alza del registro de audiencias es la necesidad de medición del tiempo de consumo en vivo y diferido. A nivel mundial se registra en 2015 una media de consumo en vivo de tres horas y 46 minutos junto a 15 minutos en diferido frente a tres horas y $58 \mathrm{mi}-$ nutos en directo y 14 minutos de diferi- do en 2013. Los sistemas de audimetría de televisión, además de la medición del consumo en vivo, están incorporando también el registro de otras formas de ver la televisión. En 2016 medían ya en 31 países el diferido, en 21 el vídeo bajo demanda, en 14 la conexión a través de computadoras y en 6 el acceso mediante tabletas y teléfonos inteligentes.

Las métricas cuantitativas de audiencias y Big Data ayudan a cuantificar el modelo de negocio de comercialización de la publicidad pero no aportan utilidad global para evaluar el impacto social y el valor intrínseco de la comunicación. 
Para eso son necesarios indicadores compuestos o sintéticos, más complejos, basados en combinaciones cuantitativas y cualitativas de datos que permitan aproximar un concepto u objeto multidimensional en una escala única para poder medir el impacto social y comparar los resultados entre organizaciones. Ese es el reto que tienen actualmente la investigación de audiencias y los modelos de negocio de las organizaciones.

La evaluación del valor intrínseco y de su impacto es una de las preocupaciones de interés de la radiotelevisión pública en Europa para fundamentar su diferenciación, legitimación y financiación como servicio audiovisual público. Las grandes corporaciones europeas de radiotelevisión pública buscan sistemas adecuados para evaluar y comunicar mejor el impacto social de sus servicios de comunicación.

\section{Metodología del Barómetro Latinoamericano}

Una vez identificadas las tendencias globales de la industria de la comunicación, el objetivo de la investigación era contrastar esas grandes líneas con la percepción del panorama latinoamericano a través de una encuesta general a los gestores de los empresas de medios de la región. Se realizó una base de datos de nombres, direcciones de contacto y niveles jerárquicos de gerentes, gestores y líderes de las áreas de gestión de 1.900 empresas relacionadas con medios de comunicación de Argentina, Bolivia, Brasil, Chile, Colombia, Costa Rica, Cuba, República Dominicana, Ecuador, El Salvador, Guatemala, Honduras,
México, Nicaragua, Panamá, Paraguay, Perú, Uruguay y Venezuela. Se elaboró un cuestionario de 12 preguntas y se distribuyó de forma directa a través de correo electrónico, mediante cartas corporativas personalizadas, con refuerzo telefónico para lograr objetivos muestrales representativos y respuestas válidas completas. En el diseño y recogida de la información trabajaron 8 personas.

Al final del proceso se obtuvieron 166 respuestas válidas, que se corresponden con un nivel de confianza del $99 \%$ y un margen de error del $9,58 \%$. Por sectores, un 22,89\% de las respuestas correspondieron a gestores de empresas de prensa, $13,86 \%$ a radio, $59,64 \%$ a televisión, $2,41 \%$ a agencias de prensa, $0,60 \%$ a medios digitales y $0,60 \%$ a agencias de publicidad. Por países el porcentaje de respuestas fue: 7,83\% Argentina; 6,63\% Bolivia; 1,2\% Brasil; $7,83 \%$ Chile; 9,64\% Colombia; 5,42\% Costa Rica; 0,62\% República Dominicana; $31,33 \%$ Ecuador; $2,41 \%$ El Salvador; Guatemala, 4,82\%; Honduras, 7,23\%; México, 1,81\%; Nicaragua, 1,2\%; Panamá, 0,66\%; Paraguay, 4,22\%; Perú, 3,01\%; y Venezuela, 0,60\%. En la base de datos de medios se incluyó también Cuba pero no fue posible obtener ninguna respuesta válida para la encuesta.

Por tamaño de las organizaciones consultadas, el 12,73\% correspondió a empresas de más de 250 empleados; el $46,67 \%$ entre 50 y 250 trabajadores; el $35,76 \%$ de 10 a 49 operarios; y el $4,85 \%$ a menos de 8 asalariados. Esta representación organizacional se corresponde a la clasificación tradicional de grandes 
empresas, medianas, pequeñas y microempresas. Las tres preguntas de la encuesta que centran este artículo se refieren a las previsiones de evolución anual de cada uno de los segmentos de la industria de la comunicación de cada país para tres años (2017, 2018 y 2019); la opinión de si los modelos tradicionales de negocio de los medios están en crisis; y la valoración que cada empresa atribuía tanto a dichos sistemas de financiación como a los nuevos modelos de negocio emergentes.

\section{Resultados y tendencias del Barómetro Latinoamericano}

El Barómetro Internacional de Gestión de Medios de Comunicación, realizado a partir de los meses de septiembre y octubre de 2016 en 19 países latinoamericanos, confirma a nivel regional las tendencias apuntadas por la Asociación Mundial de Diarios, el informe sectorial global de la consultora PWC y otros estudios generales citados en este estudio. Las opiniones de los gestores de 166 medios de comunicación de dichos países son bastante coincidentes con las tendencias globales, como se refleja en los cuadros siguientes.

En el cuadro 8 se refleja la representación gráfica de las respuestas de los gestores latinoamericanos sobre las previsiones de crecimiento hasta 2020.

Cuadro 8. Le pedimos que estime las previsiones de evolución anual de cada uno de los segmentos de la industria mediática de su país para los próximos 3 años

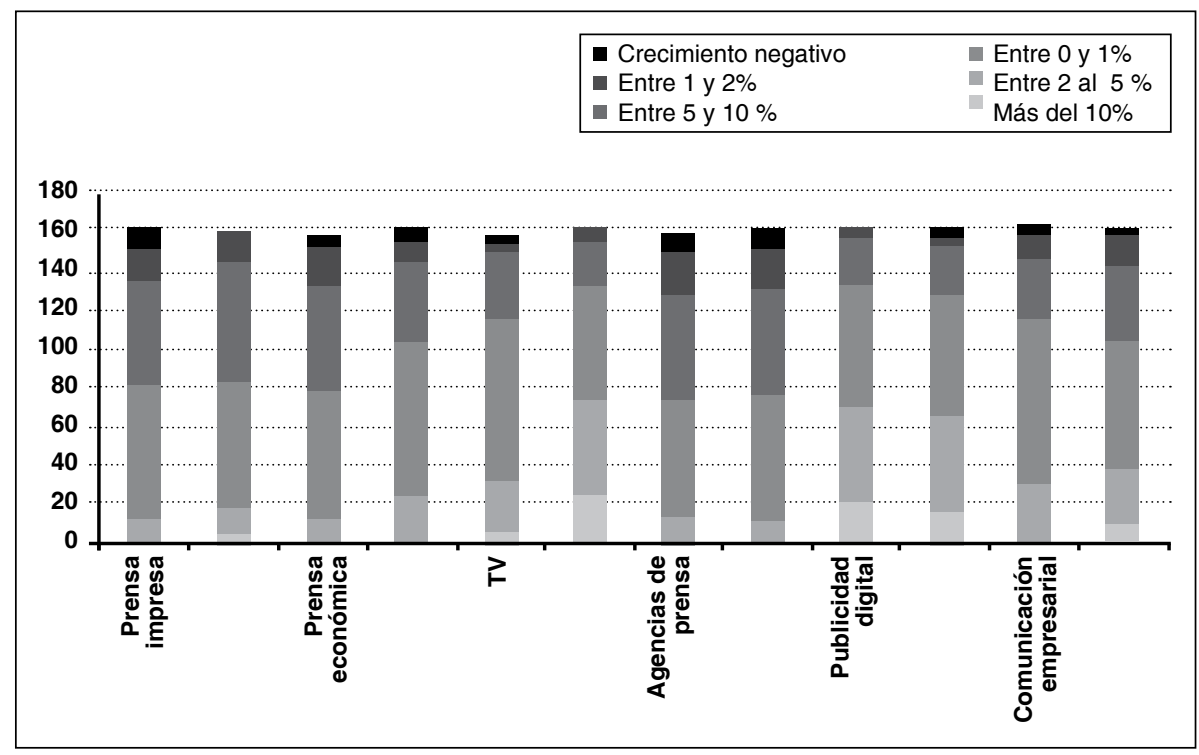

Fuente: Barómetro Internacional de Gestión de Medios, 2016. 
La opinión mayoritaria de los gestores de medios de comunicación latinoamericanos sobre las perspectivas de la prensa impresa de información general en su área hasta 2020, según esta encuesta del Barómetro de Gestión de Medios, es de un crecimiento entre el 1 y el $5 \%$, aunque con cerca de un $7 \%$ de valoración negativa. Los datos más pesimistas, cifrados en resultados negativos, corresponden a las previsiones de evolución de la prensa impresa y la publicidad tradicional, con un respectivo once y diez por ciento de opiniones que se pronuncian claramente por un crecimiento negativo en dichos sectores en los próximos tres años.

Esa misma estimación negativa sobre el modelo de negocio de la prensa impresa de información general se sitúa igualmente por debajo del $1 \%$ en una encuesta similar realizada en España (Campos, Ruas, López \& Martínez-Fernández, 2016). La misma tendencia, con pequeñas variaciones porcentuales, se aprecia con respecto a la prensa especializada deportiva y de información económica.

La opinión sobre la evolución de la radio en el ámbito latinoamericano es parecida, aunque aumenta el porcentaje $(13,5 \%)$ de los que opinan que su crecimiento puede oscilar entre el 5 y el 10 por ciento. Esa ten- dencia favorable se eleva a un 17,5 por ciento de aquellos que estiman el incremento del negocio de la televisión entre un 5\% y un $10 \%$ en los próximos tres años, junto al 52,5\% de los que cifran el crecimiento de esa actividad entre el 2 y el $5 \%$, frente a un $22,5 \%$ que ponderan el alza audiovisual entre el 1 y el 2 por ciento. Entre el 2 y el $5 \%$ o el $1 \%$ y el $2 \%$ calculan el $38,13 \%$ y el $35 \%$, respectivamente, de los encuestados el incremento de la actividad económica de las agencias de prensa.

El 12,96\% de los encuestados cifran el crecimiento de la publicidad tradicional alrededor del $1 \%$, el $35,95 \%$ la sitúan entre el 1 y el $2 \%$, el $40,74 \%$ entre el 2 y el $5 \%$ y el $6,17 \%$ del $5 \%$ al $10 \%$. Sin embargo, con respecto a la publicidad digital, ya un $12,35 \%$ de los consultados cree que crecerá más del 10\%, el 30,25 opina que lo hará entre el 5 y el $10 \%$, el $38,89 \%$ que se situará entre el 2 y el $5 \%$ y un $16,05 \%$ aún mantiene su evolución entre el 1 y el $2 \%$.

La publicidad en medios móviles la sitúan en porcentajes similares, aunque con bastante menos entusiasmo y optimismo. La opinión mayoritaria sobre la comunicación empresarial y política oscila entre el $1 \%$ y el $5 \%$, con un $17,18 \%$ y un 19,14 , respectivamente, de los que señalan que puede situarse entre el 5 y el $10 \%$ de crecimiento. 
Cuadro 9. Opiniones sobre la evolución de la industria mediática

\begin{tabular}{|c|c|c|c|c|c|c|c|}
\hline $\begin{array}{l}\text { Industria } \\
\text { mediática }\end{array}$ & $\begin{array}{l}\text { Evolución } \\
\text { negativa }\end{array}$ & $\begin{array}{l}\text { Entre } 0 \\
\text { y } 1 \%\end{array}$ & $\begin{array}{l}\text { Entre } 1 \\
\text { y } 2 \%\end{array}$ & $\begin{array}{l}\text { Entre } 2 \\
\text { al } 5 \%\end{array}$ & $\begin{array}{l}\text { Entre } 5 \\
\text { y } 10 \%\end{array}$ & $\begin{array}{l}\text { Más del } \\
10 \%\end{array}$ & Total \\
\hline $\begin{array}{l}\text { Prensa impresa } \\
\text { de información } \\
\text { general }\end{array}$ & $\begin{array}{l}6,79 \% \\
11\end{array}$ & $\begin{array}{l}9,26 \% \\
15\end{array}$ & $\begin{array}{l}32,72 \% \\
53\end{array}$ & $\begin{array}{l}44,44 \% \\
72\end{array}$ & $\begin{array}{l}6,79 \% \\
11\end{array}$ & $\begin{array}{l}0,00 \% \\
0\end{array}$ & 162 \\
\hline $\begin{array}{l}\text { Prensa } \\
\text { deportiva }\end{array}$ & $\begin{array}{l}1,23 \% \\
2\end{array}$ & $\begin{array}{l}9,20 \% \\
15\end{array}$ & $\begin{array}{l}38,65 \% \\
63\end{array}$ & $\begin{array}{l}40,49 \% \\
66\end{array}$ & $\begin{array}{l}8,59 \% \\
14\end{array}$ & $\begin{array}{l}1,84 \% \\
3\end{array}$ & 163 \\
\hline $\begin{array}{l}\text { Prensa } \\
\text { económica }\end{array}$ & $\begin{array}{l}3,14 \% \\
5\end{array}$ & $\begin{array}{l}13,21 \% \\
21\end{array}$ & $\begin{array}{l}34,59 \% \\
55\end{array}$ & $\begin{array}{l}41,51 \% \\
66\end{array}$ & $\begin{array}{l}7,55 \% \\
12\end{array}$ & $\begin{array}{l}0,00 \% \\
0\end{array}$ & 159 \\
\hline Radio & $\begin{array}{l}4,29 \% \\
7\end{array}$ & $\begin{array}{l}6,75 \% \\
11\end{array}$ & $\begin{array}{l}25,77 \% \\
42\end{array}$ & $\begin{array}{l}49,08 \% \\
80\end{array}$ & $\begin{array}{l}13,50 \% \\
22\end{array}$ & $\begin{array}{l}0,61 \% \\
1\end{array}$ & 163 \\
\hline TV & $\begin{array}{l}3,75 \% \\
6\end{array}$ & $\begin{array}{l}1,88 \% \\
3\end{array}$ & $\begin{array}{l}22,50 \% \\
36\end{array}$ & $\begin{array}{l}52,50 \% \\
84\end{array}$ & $\begin{array}{l}17,50 \% \\
28\end{array}$ & $\begin{array}{l}1,88 \% \\
3\end{array}$ & 160 \\
\hline $\begin{array}{l}\text { Medios } \\
\text { digitales }\end{array}$ & $\begin{array}{l}0,62 \% \\
1\end{array}$ & $\begin{array}{l}3,09 \% \\
5\end{array}$ & $\begin{array}{l}14,81 \% \\
24\end{array}$ & $\begin{array}{l}35,80 \% \\
58\end{array}$ & $\begin{array}{l}32,10 \% \\
52\end{array}$ & $\begin{array}{l}13,58 \% \\
22\end{array}$ & 162 \\
\hline $\begin{array}{l}\text { Agencias de } \\
\text { prensa }\end{array}$ & $\begin{array}{l}5,63 \% \\
9\end{array}$ & $\begin{array}{l}13,75 \% \\
22\end{array}$ & $\begin{array}{l}35,00 \% \\
56\end{array}$ & $\begin{array}{l}38,13 \% \\
61\end{array}$ & $\begin{array}{l}6,88 \% \\
11\end{array}$ & $\begin{array}{l}0,63 \% \\
1\end{array}$ & 160 \\
\hline $\begin{array}{l}\text { Publicidad } \\
\text { tradicional }\end{array}$ & $\begin{array}{l}6,17 \% \\
10\end{array}$ & $\begin{array}{l}12,96 \% \\
21\end{array}$ & $\begin{array}{l}33,95 \% \\
55\end{array}$ & $\begin{array}{l}40,74 \% \\
66\end{array}$ & $\begin{array}{l}6,17 \% \\
10\end{array}$ & $\begin{array}{l}0,00 \% \\
0\end{array}$ & 162 \\
\hline $\begin{array}{l}\text { Publicidad } \\
\text { digital }\end{array}$ & $\begin{array}{l}1,23 \% \\
2\end{array}$ & $\begin{array}{l}1,23 \% \\
2\end{array}$ & $\begin{array}{l}16,05 \% \\
26\end{array}$ & $\begin{array}{l}38,89 \% \\
63\end{array}$ & $\begin{array}{l}30,25 \% \\
49\end{array}$ & $\begin{array}{l}12,35 \% \\
20\end{array}$ & 162 \\
\hline $\begin{array}{l}\text { Publicidad en } \\
\text { medios móviles }\end{array}$ & $\begin{array}{l}2,45 \% \\
4\end{array}$ & $\begin{array}{l}2,45 \% \\
4\end{array}$ & $\begin{array}{l}16,56 \% \\
27\end{array}$ & $\begin{array}{l}38,04 \% \\
62\end{array}$ & $\begin{array}{l}31,90 \% \\
52\end{array}$ & $\begin{array}{l}8,59 \% \\
14\end{array}$ & 163 \\
\hline $\begin{array}{l}\text { Comunicación } \\
\text { empresarial }\end{array}$ & $\begin{array}{l}0,61 \% \\
1\end{array}$ & $\begin{array}{l}8,59 \% \\
14\end{array}$ & $\begin{array}{l}20,25 \% \\
33\end{array}$ & $\begin{array}{l}52,15 \% \\
85\end{array}$ & $\begin{array}{l}17,18 \% \\
28\end{array}$ & $\begin{array}{l}1,23 \% \\
2\end{array}$ & 163 \\
\hline $\begin{array}{l}\text { Comunicación } \\
\text { política }\end{array}$ & $\begin{array}{l}0,62 \% \\
1\end{array}$ & $\begin{array}{l}10,49 \% \\
17\end{array}$ & $\begin{array}{l}24,69 \% \\
40\end{array}$ & $\begin{array}{l}41,98 \% \\
68\end{array}$ & $\begin{array}{l}19,14 \% \\
31\end{array}$ & $\begin{array}{l}3,09 \% \\
5\end{array}$ & 162 \\
\hline
\end{tabular}

Fuente: Barómetro Internacional de Gestión de Medios, 2016.

La valoración general sobre la coyuntura industrial sectorial es más favorable por parte de los gestores de medios de los países latinoamericanos que por la de sus colegas a nivel mundial y de España, en particular; pero se vuelve coincidente cuando se pregunta por la existencia o no de crisis en el modelo de negocio de la prensa impresa de pago. Los cuadros 10 y 11 muestran las valoraciones sobre los respectivos modelos de negocio. 
Cuadro 10. ¿Cree que los modelos de negocio de los medios (prensa, radio y televisión) están en crisis? Marque la respuesta según las categorías siguientes

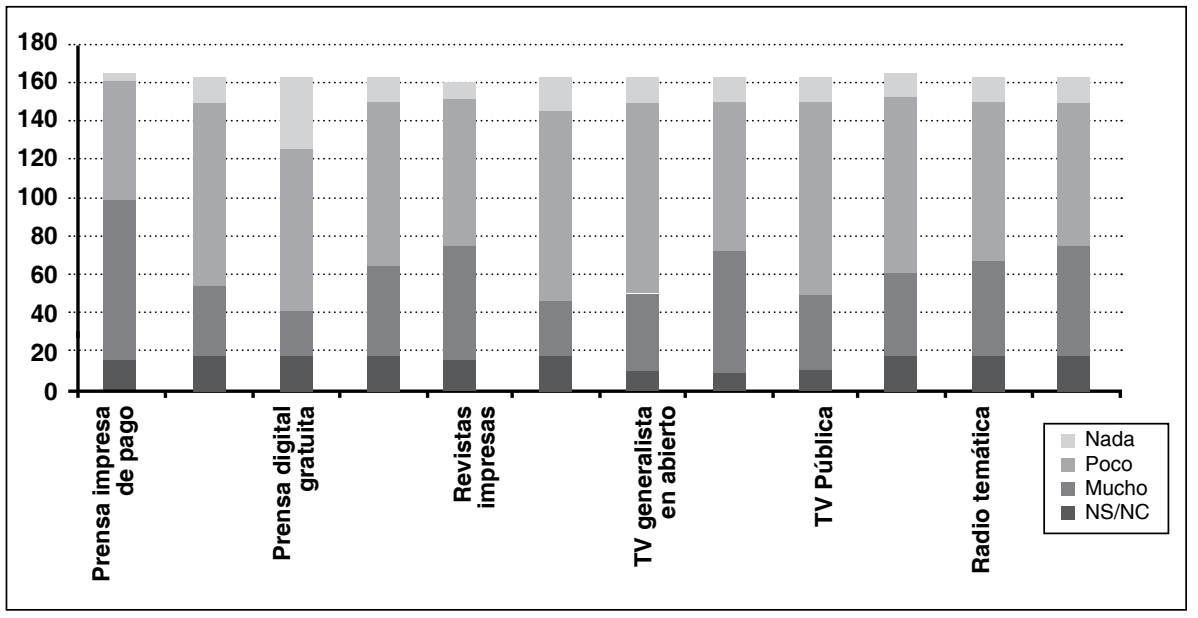

Fuente: Barómetro Internacional de Gestión de Medios, 2016.

La pregunta sobre la crisis de los modelos de negocio de los medios pondera las valoraciones en tres categorías: nada, poco y mucho, dejando abierta la opción de no sabe/no contesta. El 50,31por ciento de los encuestados considera que el modelo de negocio mixto tradicional (pago y publicidad) de la prensa impresa está muy en crisis. Sin embargo, todavía una mayoría $(57,41 \%)$ de los consultados opina que la prensa impresa gratuita es viable porque está poco en crisis. Esta opinión sobre la prensa gratuita contrasta con la percepción y la realidad de este subsector en Europa, donde este modelo impreso está agotado y prácticamente extinguido.

La tendencia mayoritaria positiva entre los encuestados se refleja en las opiniones sobre los siguientes modelos que consideran poco afectados por la crisis: prensa digital gratuita, muro de pago digital (paywall), revistas digitales, televisión generalista en abierto, televisión pública, radio generalista y radio temática. La confianza en la televisión de pago codificada y las agencias de prensa es positiva aunque con menos entusiasmo. 
Cuadro 11. Valoración sobre los modelos de negocio de los medios

\begin{tabular}{|c|c|c|c|c|c|}
\hline Medios & Nada & Poco & Mucho & NS/NC & Total \\
\hline Prensa impresa de pago & $\begin{array}{l}0,61 \% \\
1\end{array}$ & $\begin{array}{l}39,26 \% \\
64\end{array}$ & $\begin{array}{l}50,31 \% \\
82\end{array}$ & $\begin{array}{l}9,82 \% \\
16\end{array}$ & 163 \\
\hline Prensa impresa gratis & $\begin{array}{l}8,64 \% \\
14\end{array}$ & $\begin{array}{l}57,41 \% \\
93\end{array}$ & $\begin{array}{l}23,46 \% \\
38\end{array}$ & $\begin{array}{l}10,49 \% \\
17\end{array}$ & 162 \\
\hline Prensa digital gratuita & $\begin{array}{l}22,84 \% \\
37\end{array}$ & $\begin{array}{l}53,09 \% \\
86\end{array}$ & $\begin{array}{l}13,58 \% \\
22\end{array}$ & $\begin{array}{l}10,49 \% \\
17\end{array}$ & 162 \\
\hline Prensa digital de pago (paywall) & $\begin{array}{l}6,83 \% \\
11\end{array}$ & $\begin{array}{l}53,42 \% \\
86\end{array}$ & $\begin{array}{l}28,57 \% \\
46\end{array}$ & $\begin{array}{l}11,18 \% \\
18\end{array}$ & 161 \\
\hline Revistas impresas & $\begin{array}{l}6,21 \% \\
10\end{array}$ & $\begin{array}{l}47,20 \% \\
76\end{array}$ & $\begin{array}{l}37,89 \% \\
61\end{array}$ & $\begin{array}{l}8,70 \% \\
14\end{array}$ & 161 \\
\hline Revistas digitales & $\begin{array}{l}9,88 \% \\
16\end{array}$ & $\begin{array}{l}61,11 \% \\
99\end{array}$ & $\begin{array}{l}17,28 \% \\
28\end{array}$ & $\begin{array}{l}11,73 \% \\
19\end{array}$ & 162 \\
\hline TV generalista en abierto & $\begin{array}{l}8,59 \% \\
14\end{array}$ & $\begin{array}{l}60,74 \% \\
99\end{array}$ & $\begin{array}{l}23,93 \% \\
39\end{array}$ & $\begin{array}{l}6,75 \% \\
11\end{array}$ & 163 \\
\hline TV de pago codificada & $\begin{array}{l}7,41 \% \\
12\end{array}$ & $\begin{array}{l}47,53 \% \\
77\end{array}$ & $\begin{array}{l}39,51 \% \\
64\end{array}$ & $\begin{array}{l}5,56 \% \\
9\end{array}$ & 162 \\
\hline TVPública & $\begin{array}{l}7,41 \% \\
12\end{array}$ & $\begin{array}{l}61,73 \% \\
100\end{array}$ & $\begin{array}{l}23,46 \% \\
38\end{array}$ & $\begin{array}{l}7,41 \% \\
12\end{array}$ & 162 \\
\hline Radio generalista & $\begin{array}{l}7,27 \% \\
12\end{array}$ & $\begin{array}{l}55,15 \% \\
91\end{array}$ & $\begin{array}{l}26,67 \% \\
44\end{array}$ & $\begin{array}{l}10,91 \% \\
18\end{array}$ & 165 \\
\hline Radio temática & $\begin{array}{l}7,41 \% \\
12\end{array}$ & $\begin{array}{l}51,23 \% \\
83\end{array}$ & $\begin{array}{l}30,86 \% \\
50\end{array}$ & $\begin{array}{l}10,49 \% \\
17\end{array}$ & 162 \\
\hline Agencias de prensa & $\begin{array}{l}8,64 \% \\
14\end{array}$ & $\begin{array}{l}45,06 \% \\
73\end{array}$ & $\begin{array}{l}35,80 \% \\
58\end{array}$ & $\begin{array}{l}10,49 \% \\
17\end{array}$ & 162 \\
\hline
\end{tabular}

Fuente: Barómetro Internacional de Gestión de Medios, 2016.

Los cuadros 12 y 13 recogen las estimaciones, a futuro inmediato, de los gestores de medios latinoamericanos sobre los distintos modelos de negocio como instrumento de financiación, en una escala de 1 a 10. El modelo de negocio es un instrumento de política comer- cial y de financiación. Por eso se plantea la pregunta en esa doble vertiente.

La venta de ejemplares de la prensa de pago concita la mayor cota de confianza entre los gestores de medios de comunicación, aunque también empiezan a prestarle atención al pago a través 
de las ediciones digitales. La venta de ejemplares se sitúa por encima de la publicidad como sistema de financia- ción más sostenible a largo plazo, pero el patrocinio es mejor valorado que el sistema publicitario tradicional.

Cuadro 12. Indique la importancia que le atribuye a los siguientes modelos de negocio/ financiación de los distintos medios de cara al futuro inmediato, a partir de una escala de 1 a 10 (teniendo en cuenta que 1 es mínimo y 10 máximo).

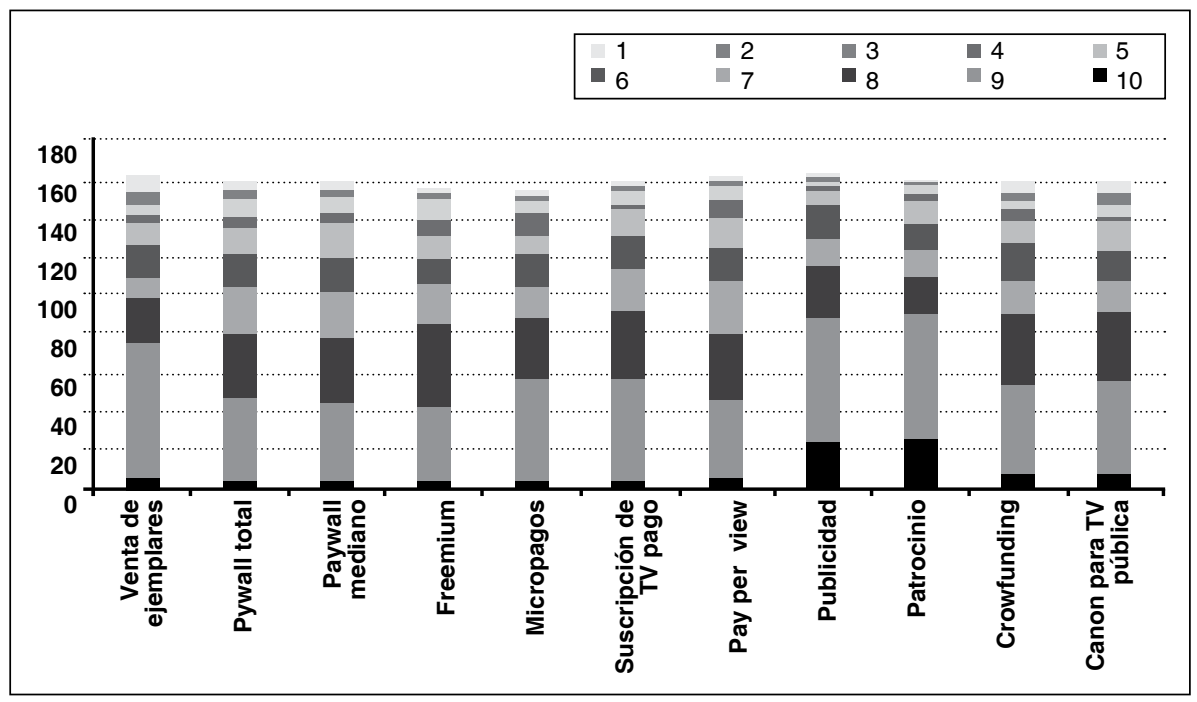

Fuente: Barómetro Internacional de Gestión de Medios, 2016.

El muro de pago total (paywall cerrado) alcanza cerca de un $50 \%$ de interés entre los gestores latinoamericanos, al igual que el paywall mediado (modelo The New York Times, acceso abierto a un número de noticias por mes), el freemium (partes generalistas abiertas $\mathrm{y}$ otras de más valor o exclusividad cerradas) y los micropagos.

La suscripción de la televisión de pago es mejor valorada que el pago por visión (pay per viw) aunque también destaca el interés por el crowfunding y el canon de la televisión de pago, este último como ejemplo de financiación dominante de la radiotelevisión pública en varios países europeos. El significado de las respuestas relacionadas con la última pregunta comentada en este trabajo hay que concebirlo más como deseo o interés de los gestores encuestados que como realidad prospectiva inmediata. 
Cuadro 13. Modelos de negocio como fuente de financiación

\begin{tabular}{|c|c|c|c|c|c|c|c|c|c|c|c|}
\hline $\begin{array}{l}\text { Fuente de } \\
\text { financiación }\end{array}$ & 1 & 2 & 3 & 4 & 5 & 6 & 7 & 8 & 9 & 10 & Total \\
\hline $\begin{array}{l}\text { Venta de } \\
\text { ejemplares }\end{array}$ & $\begin{array}{l}4,29 \% \\
7\end{array}$ & $\begin{array}{l}4,29 \% \\
7\end{array}$ & $\begin{array}{l}3,68 \% \\
6\end{array}$ & $\begin{array}{l}2,45 \% \\
4\end{array}$ & $\begin{array}{l}6,75 \% \\
11\end{array}$ & $\begin{array}{l}10,43 \% \\
17\end{array}$ & $\begin{array}{l}6,75 \% \\
11\end{array}$ & $\begin{array}{l}14,72 \% \\
24\end{array}$ & $\begin{array}{l}42,94 \% \\
70\end{array}$ & $\begin{array}{l}3,68 \% \\
6\end{array}$ & 163 \\
\hline Paywall total & $\begin{array}{l}2,50 \% \\
4\end{array}$ & $\begin{array}{l}2,50 \% \\
4\end{array}$ & $\begin{array}{l}6,25 \% \\
10\end{array}$ & $\begin{array}{l}3,75 \% \\
6\end{array}$ & $\begin{array}{l}8,75 \% \\
14\end{array}$ & $\begin{array}{l}10,63 \% \\
17\end{array}$ & $\begin{array}{l}15,00 \% \\
24\end{array}$ & $\begin{array}{l}20,63 \% \\
33\end{array}$ & $\begin{array}{l}27,50 \% \\
44\end{array}$ & $\begin{array}{l}2,50 \% \\
4\end{array}$ & 160 \\
\hline $\begin{array}{l}\text { Paywall } \\
\text { mediado }\end{array}$ & $\begin{array}{l}2,52 \% \\
4\end{array}$ & $\begin{array}{l}1,26 \% \\
2\end{array}$ & $\begin{array}{l}6,29 \% \\
10\end{array}$ & $\begin{array}{l}3,14 \% \\
5\end{array}$ & $\begin{array}{l}11,32 \% \\
18\end{array}$ & $\begin{array}{l}11,32 \% \\
18\end{array}$ & $\begin{array}{l}14,47 \% \\
23\end{array}$ & $\begin{array}{l}22,64 \% \\
36\end{array}$ & $\begin{array}{l}24,53 \% \\
39\end{array}$ & $\begin{array}{l}2,52 \% \\
4\end{array}$ & 159 \\
\hline Freemium & $\begin{array}{l}1,92 \% \\
3\end{array}$ & $\begin{array}{l}1,28 \% \\
2\end{array}$ & $\begin{array}{l}7,05 \% \\
11\end{array}$ & $\begin{array}{l}5,77 \% \\
9\end{array}$ & $\begin{array}{l}8,33 \% \\
13\end{array}$ & $\begin{array}{l}7,69 \% \\
12\end{array}$ & $\begin{array}{l}13,46 \% \\
21\end{array}$ & $\begin{array}{l}28,21 \% \\
44\end{array}$ & $\begin{array}{l}24,36 \% \\
38\end{array}$ & $\begin{array}{l}1,92 \% \\
3\end{array}$ & 156 \\
\hline Micropagos & $\begin{array}{l}1,92 \% \\
3\end{array}$ & $\begin{array}{l}2,56 \% \\
4\end{array}$ & $\begin{array}{l}3,85 \% \\
6\end{array}$ & $\begin{array}{l}7,05 \% \\
11\end{array}$ & $\begin{array}{l}7,05 \% \\
11\end{array}$ & $\begin{array}{l}10,90 \% \\
17\end{array}$ & $\begin{array}{l}9,62 \% \\
15\end{array}$ & $\begin{array}{l}20,51 \% \\
32\end{array}$ & $\begin{array}{l}33,97 \% \\
53\end{array}$ & $\begin{array}{l}2,56 \% \\
4\end{array}$ & 156 \\
\hline $\begin{array}{l}\text { Suscripción } \\
\text { de TV pago }\end{array}$ & $\begin{array}{l}1,27 \% \\
2\end{array}$ & $\begin{array}{l}0,63 \% \\
1\end{array}$ & $\begin{array}{l}4,43 \% \\
7\end{array}$ & $\begin{array}{l}1,27 \% \\
2\end{array}$ & $\begin{array}{l}9,49 \% \\
15\end{array}$ & $\begin{array}{l}10,76 \% \\
17\end{array}$ & $\begin{array}{l}13,92 \% \\
22\end{array}$ & $\begin{array}{l}22,15 \% \\
35\end{array}$ & $\begin{array}{l}34,18 \% \\
54\end{array}$ & $\begin{array}{l}1,90 \% \\
3\end{array}$ & 158 \\
\hline Pay per view & $\begin{array}{l}1,24 \% \\
2\end{array}$ & $\begin{array}{l}2,48 \% \\
4\end{array}$ & $\begin{array}{l}3,11 \% \\
5\end{array}$ & $\begin{array}{l}5,59 \% \\
9\end{array}$ & $\begin{array}{l}9,32 \% \\
15\end{array}$ & $\begin{array}{l}11,18 \% \\
18\end{array}$ & $\begin{array}{l}17,39 \% \\
28\end{array}$ & $\begin{array}{l}21,74 \% \\
35\end{array}$ & $\begin{array}{l}25,47 \% \\
41\end{array}$ & $\begin{array}{l}2,48 \% \\
4\end{array}$ & 161 \\
\hline Publicidad & $\begin{array}{l}0,62 \% \\
1\end{array}$ & $\begin{array}{l}0,62 \% \\
1\end{array}$ & $\begin{array}{l}1,85 \% \\
3\end{array}$ & $\begin{array}{l}1,23 \% \\
2\end{array}$ & $\begin{array}{l}4,32 \% \\
7\end{array}$ & $\begin{array}{l}11,11 \% \\
18\end{array}$ & $\begin{array}{l}8,64 \% \\
14\end{array}$ & $\begin{array}{l}17,28 \% \\
28\end{array}$ & $\begin{array}{l}39,51 \% \\
64\end{array}$ & $\begin{array}{l}14,81 \% \\
24\end{array}$ & 162 \\
\hline Patrocinio & $\begin{array}{l}1,26 \% \\
2\end{array}$ & $\begin{array}{l}1,26 \% \\
2\end{array}$ & $\begin{array}{l}1,26 \% \\
2\end{array}$ & $\begin{array}{l}1,89 \% \\
3\end{array}$ & $\begin{array}{l}7,55 \% \\
12\end{array}$ & $\begin{array}{l}8,81 \% \\
14\end{array}$ & $\begin{array}{l}8,81 \% \\
14\end{array}$ & $\begin{array}{l}12,58 \% \\
20\end{array}$ & $\begin{array}{l}40,88 \% \\
65\end{array}$ & $\begin{array}{l}15,72 \% \\
25\end{array}$ & 159 \\
\hline Crowfunding & $\begin{array}{l}3,14 \% \\
5\end{array}$ & $\begin{array}{l}3,14 \% \\
5\end{array}$ & $\begin{array}{l}2,52 \% \\
4\end{array}$ & $\begin{array}{l}3,77 \% \\
6\end{array}$ & $\begin{array}{l}7,55 \% \\
12\end{array}$ & $\begin{array}{l}11,32 \% \\
18\end{array}$ & $\begin{array}{l}11,95 \% \\
19\end{array}$ & $\begin{array}{l}22,64 \% \\
36\end{array}$ & $\begin{array}{l}29,56 \% \\
47\end{array}$ & $\begin{array}{l}4,40 \% \\
7\end{array}$ & 159 \\
\hline $\begin{array}{l}\text { Canon para } \\
\text { TV pública }\end{array}$ & $\begin{array}{l}4,38 \% \\
7\end{array}$ & $\begin{array}{l}3,75 \% \\
6\end{array}$ & $\begin{array}{l}3,13 \% \\
5\end{array}$ & $\begin{array}{l}1,88 \% \\
3\end{array}$ & $\begin{array}{l}10,00 \% \\
16\end{array}$ & $\begin{array}{l}8,75 \% \\
14\end{array}$ & $\begin{array}{l}10,00 \% \\
16\end{array}$ & $\begin{array}{l}23,75 \% \\
38\end{array}$ & $\begin{array}{l}30,63 \% \\
49\end{array}$ & $\begin{array}{l}3,75 \% \\
6\end{array}$ & 160 \\
\hline
\end{tabular}

Fuente: Barómetro Internacional de Gestión de Medios, 2016.

\section{Conclusiones}

A pesar de las tendencias globales de cambio y de los resultados negativos concretos en algunos medios tradicionales -principalmente en la prensa impresa- en determinados países, las perspectivas de evolución a tres años vista de la industria mediática en América Latina son más favorables que en otras partes del mundo si tomamos como referencia el recuento de las opiniones de los gestores de las empresas de comunicación registradas a través de la encuesta realizada por esta investigación.
El Barómetro Latinoamericano de Gestión de Medios de Comunicación constata, por su parte, una coincidencia general con la tendencia global del sector al cifrar las mayores expectativas de crecimiento en los próximos años en torno a la publicidad digital, los medios digitales y la comunicación móvil. La evolución real de la publicidad en los medios de comunicación de esos países ha sido positiva en los últimos años, pero absorbida principalmente por la televisión y los nuevos sistemas digitales. 
La crisis del modelo de negocio mixto tradicional de la prensa impresa (debido al descenso de la publicidad y a la caída de los ingresos por el pago de ejemplares), cuya percepción comparten una mayoría de gestores de medios, despierta a su vez el interés en las empresas por otras formas de financiación tales como el muro de pago, el patrocinio o el crowfunding. Incluso los gestores miran con esperanza las posibilidades de la prensa gratuita, un modelo agotado en otras partes del mundo, pero que en algunos países latinoamericanos aún se contempla como una alternativa de captación de públicos populares masivos tradicionalmente ajenos a este medio histórico concebido como soporte político de élites.

La carencia de fuentes solventes y de datos homogéneos para el conjunto de los países no permite suscribir conclusiones contundentes más allá de la prudencia que requiere la ausencia de tales sistemas de información. De los datos de conjunto disponibles, sí se puede constar la fragmentación de audiencias en el sistema de televisión, salvo en los países de Brasil, Perú, Panamá y Paraguay, con porcentajes de concentración similares o inferiores a los de algunos de los operadores de los duopolios presentes en los países europeos.

La convergencia digital no sólo es trascendente en los modelos de producción y distribución de la información sino también en los sistemas de medición, valorización, cuantificación, monetización y financiación. Por eso la conclusión general de este trabajo con respecto a los modelos de negocio de los medios en América del Sur, a pesar de las perspectivas menos desfavorables del corto plazo, es que las tendencias globales acabarán afectando en el mismo sentido en la región. La convergencia digital tiende a imponer sus lógicas globales.

\section{Reconocimiento de investigación}

Los resultados de este artículo corresponden a una iniciativa desarrollada dentro del Programa Prometeo del SENESCYT de Ecuador en el período 2014-2016, comprendida también dentro del proyecto de "Indicadores de gobernanza, financiación, rendición de cuentas, innovación, calidad y servicio público de las RTV europeas aplicables a España en el contexto digital" (Referencia CSO2015-66543-P) de Fomento de la Investigación Científica y Técnica de Excelencia, subprograma estatal de Generación de Conocimiento del Ministerio de Economía y Competitividad de España, cofinanciado por el Fondo Europeo de Desarrollo Regional (FEDER) de la Unión Europea. Así como de la actividad de la Red Internacional de Investigación de Gestión de la Comunicación (REDES 2016 G-1641 XESCOM) apoyada por la Consellería de Cultura, Educación e Ordenación Universitaria de la Xunta de Galicia (referencia ED341D R2016/019). 


\section{Referencias Bibliográficas}

Allee, V. (2009). Value Creating Networks: Organizational Issues and Challenges. In The Learning Organization Special Issue on Social Networks and Social Networking, vol. 6, issue 6, 427442. Recuperado de http://citeseerx.ist.psu.edu/viewdoc/download?.

Boczkowski, P. (2004). The processes of adopting multimedia and interactivity in three online newsrooms. Journal of Communication, no 54, 197-213.

Boy, D. \& Ellison, N. (2007). Social Networks Sites: Definition, History an Scholarship. In Journal Computer-Mediated Communication, 13, 210-230.

Campos-Freire, F (2008). Las redes sociales trastocan los modelos de los medios de comunicación tradicionales. En Revista Latina de Comunicación Social, 63, 287-292.

Campos-Freire, F. (2015). Adaptación de los medios tradicionales a la innovación de los metamedios. El Profesional de la Información, v. 24, n. 4, 441-450.

Campos-Freire, F., Rúas-Araújo, J., López-García, X. y Martínez-Fernández, V.A. (2016). Impacto de las redes sociales en el periodismo. El Profesional de la Información, v. 25, n. 3, 449-457.

Casero, A. (2012). Contenidos periodísticos y nuevos modelos de negocio: evaluación de servicios digitales. El Profesional de la Información, vol. 21, no.4, 341-346.

Castells, M. (2009). Comunicación y poder. Madrid: Alianza Editorial

Christensen, C. M., Raynor, M. E. y McDonald, R. (2015). What Is Disruptive Innovation?. HBR. Recuperado de https://hbr.org/2015/12/what-is-disruptive-innovation.

Cukier, K. (2016). Los Big Data y el futuro de los negocios. Recuperado de: https:/www.bbvaopenmind.com.

Dailey, L., Demo, L. y Spillman, M. (2005). The convergente continuum: a model for studying collaboration between media newsrooms. Atlantic Journal of Communications, vol. 13, no $3,150-168$.

Deloitte (2016). Analytics Trends The Nest Evolution. Recuperado de https://www2.deloitte. com/us/en/pages/deloitte-analytics/articles/analytics-trends.html. Deuze, M. (2017). Considering a possible future for Digital Journalism. Revista Mediterránea de Comunicación/ Mediterranean Journal of Communication, 8 (1), 9-18.

Díaz Nosty, B. (2007). Medios de comunicación en el escenario iberoamericano. Coordinación de la publicación e informe marco. Fundación Telefónica. Barcelona: Ariel.

Drucker, P. (1954, 2011). La práctica del Management. Madrid: Ciro Ediciones.

EBU (2012). Empowering Society: A Declaration on the Core Values of Public Service Media. Recuperado de https:/www.ebu.ch/files/live/sites/ebu/files/Publications/EB

Eurodata (2016). One TV Year on the world. París: Eurodata TV Worldwide.

European Communication Monitor (2016). Exploring trends in big data, stakeholder engagement and strategic communication. Results of a survey in 43 Countries. De Zerfass, A., Verhoeven, P., Moreno, A., Tench, R., \& Verč ič , D. Bruselas: EACD/EUPRERA, Quadriga Media Berlin.

Evans, Ph. (2015). De la deconstrucción a los big data: como la tecnología está transformando las empresas. Recuperado de https://bbvaopenmind.com. 
Hallin, D. C. y Mancini P. (2007). Un estudio comparado de los medios en América Latina, pp 91-95. En Díaz Nosty, B. (2007). Medios de comunicación en el escenario iberoamericano. Coordinación de la publicación e informe marco. Fundación Telefónica. Barcelona: Ariel.

Feng, L. y Jason, W. (2002). Deconstruction of the telecomunications industry: from value chains to value networks. Telecommunications Policy, vol. 26, 9-10, pp. 451-472.

Fontaine, G. (2015). Trends in linear televisión revenues. European Audiovisual Observatory. García Avilés, J .A. Carvajal, M. (2008). Integrated and cross-media newsroom convergente: two models of multimedia news production: the cases of Novotécnica and La verdad multimedia in Spain. Convergence, vol. 14, no 2, 223-241.

Kotter, John P. (2015). La organización del futuro: un nuevo modelo para un mundo de cambio acelerado. Recuperado de: https://bbvaopenmind.com

López, X.y Pereira, X. (2010). Convergencia digital. Reconfiguración de los medios de comunicación en España. Santiago de Compostela: Servicio de Publicaciones de la Universidad de Santiago.

Mastrini, G. y Becerra, M. (2006). Periodistas y magnates. Estructura y concentración de las industrias culturales en América Latina. Buenos Aires: Prometeo

Magretta, J. (2002). Why Business Models Matter. Harvard Business Review, 80, (5), 86-92.

Mendelson, H. (2016). Modelos de negocio, tecnologías de la información y la empresa del futuro. Recuperado de https:/www.bbvaopenmind.com/wp-content/uploads/2015/02/ BBVA-OpenMind-modelos-de-negocio-tecnologias-de-la-informacion-y-la-empresa-delfuturo-innovacion-empresarial.pdf

Miguel de Bustos, J.C. (2017). Big Data y Big GAFA (Google, Facebook, Amazon y Apple. Reflexiones sobre economía de los datos. España: Universidad del País Vasco.

Miguel de Bustos, J. C. y Casado, M. A. (2016). GAFAnomy (Google, Amazon, Facebook and Apple): The Big Four and the b-ecosystem. En Mikel Gómez-Uranga, M., ZabalaIturriagagoitia, J. M. and Barrutia, J. Dynamics of Big Internet Industry Groups and Future Trends: A View from Epigenetic Economics, Springer.

Newman, N. (2017). Journalism, Media, and Technology Trends and Predictions 2017. Digital News Project. Reuters Institute. Recuperado de http://www.digitalnewsreport.org/ OFCOM (2016). International Communications Market Report 2015. Recuperado de https://www.ofcom.org.uk

Osterwalder, A.y Pigneur, Y. (2012). Generación de modelos de negocio. Bilbao: Deusto.

Osterwalder, A., Pigneur, Y. and Tucci, C. L. (2005). Clarifying Business Models. Origins, Present, and Future of the Concept. Communications of the Association for Information Systems, vol. 16, 1. Recuperado de http://aisel.aisnet.org/cais/vol16/iss1/1.

Picard, R. (2012). La creación de valor y el futuro de las empresas informativas. Por qué y cómo el periodismo debe cambiar para seguir siendo relevante en el siglo XXI. Porto: Media XXI.

Picard, R. G., Beloir-Gagnon, V. \& Ranchordás, S. (2016). The impact of charity and tax law/ regulation on not-for-profit news organizations. Londres: Reuters Institute for the Study of Journalism.

Pryor, P. (2000). Immersive News Technology: Beyond Convergence. En USC Annenberg Online Journalism Review. Recuperado de: http://goo.gl/FMRM2X 
PWC (2016). Entertainment and Media Outlook 2016-2020 España. Recuperado de www. pwc.com.

Rocagliolo, R. (2003). Problemas de la integración cultural: América Latina. Buenos Aires: Norma Rainie, L., Anderson, J. \& Page, D. (2017). Code-Dependent: Pros an Cons of the Algorithm Age. Pew Research Instititue. Recuperado de www.pewresearch.org

Shiller, B. (2016). Will ad blocking break The Internet?. Harvard Business School

Storey, G., Reisman, D., Mayer, J. \& Narayanan, A. (2017). An Analytical Framework and New Techniques. Princeton University Recuperado de http://andomwalker.info/publications/ad-blocking-framework-techniques.pdf.

Thomson, Peter (2015). Nuevas formas de trabajar en la empresa del futuro. Recuperado de https://www.bbvaopenmind.com/articulo/nuevas-formas-de-trabajar-en-la-empresa-del-futuro/

Timmers, P. (1998). Business Models for Electronic Mrkets. European Commission. Recuperado de http://U-Empowering-Society_EN.pdf

WAN-IFRA (2015). World trends database. Asociación Mundial de Diarios, WAN-IFRA. Recuperado de http://www.wan-ifra.org

WAN-IFRA (2016). World Press Trends 2016. Recuperado de http://www.wan-ifra.org

Welman, B. (2001). Computer Networks as Social Networks. Science, 14.

WNMN (2015). World Newsmedia. Innovation Study 2015. The seventh anual survey chronicles media company priorities to manage current challenges and ensure future sucess. The World Newsmedia Innovation Study 2015 is part of a nine-part series of research reports that comprise Global Digital Media Trendbook 2015. Recuperado de http:// www.wnmn.org

Zenith (2017). Top Thirty Global Media Owners. Recuperado de https://www.zenithmedia. com/product/top-thirty-global-media-owners-2017 